\title{
AUTOMATIC GENERATION OF ROAD INFRASTRUCTURE IN 3D FOR VEHICLE SIMULATORS
}

\author{
ADAM ORLICKÝ \\ Faculty of Transportation Sciences, Czech Technical University in Prague, Konviktská 20, Prague 1, Czech \\ Republic \\ correspondence: orlicada@fd.cvut.cz
}

\begin{abstract}
One of the modern methods of testing new systems and interfaces in vehicles is testing in a vehicle simulator. Providing quality models of virtual scenes is one of tasks for driver-car interaction interface simulation. Nowadays, there exist many programs for creating 3D models of road infrastructures, but most of these programs are very expensive or canÂtt export models for the following use.

Therefore, a plug-in has been developed at the Faculty of Transportation Sciences in Prague. It can generate road infrastructure by Czech standard for designing roads (ČSN 73 6101). The uniqueness of this plug-in is that it is the first tool for generating road infrastructure in NURBS representation. This type of representation brings more exact models and allows to optimize transfer for creating quality models for vehicle simulators.

The scenes created by this plug-in were tested on vehicle simulators. The results have shown that with newly created scenes drivers had a much better feeling in comparison to previous scenes.
\end{abstract}

KEYWORDS: Vehicle simulator, Road design, 3D modeling.

\section{INTRODUCTION}

With emerging technologies, many branches of the technical sciences have appeared during the last few decades. One of such branches is computer graphics, whose one of the sections is the $3 \mathrm{D}$ modeling. It deals with displaying the real world in virtual threedimensional space. For this the 3-D modeling is used.

In road transportation $3 \mathrm{D}$ modeling is used for the planning and design of newly projected or reconstructed roads and highways. Generation of 3D models in special software is usually restricted by local laws, besides, the price of the software is rather high. Most of these applications allow to create project documentation for the designed roadways, display the developed models in 3D and, in the case of highly sophisticated software, create visualization and animation. Typically, exporting is not really possible, that is why this software can't be used for other purposes [1].

In transportation, virtual reality is widely used in creation of interactive vehicle simulators. The real world can be displayed in virtual scenes with the help of projectors, or on monitors. One of the advantages of exploitation of driving simulators is a possibility to evaluate driver behavior in the conditions and situations that are precisely set up in driving scenarios. It is important that while driving the simulator a driver would get a feeling maximally approaching the experience of real driving. Quality 3D models can contribute to the improvement of the visual perception. In most modern driver simulators, the road infrastructure isn't generated according to these standards.

All of this provides a motivation for the creation of a tool (as a plug-in for 3D modeling program) which is able to generate $3 \mathrm{D}$ road infrastructures according to Czech Standard 2, developed for a minimal price and for wide-ranging applications. For this purpose, we were looking for a software, where both design drawing and 3D modeling are possible.

Besides the generation of road infrastructure models, a tool (plug-in) should be able to complete a scene around roads in such a way, that the resulting virtual scenery would be as close to reality as possible.

\subsection{Driving Simulator SCEnE REQUIREMENTS}

There are rather specific requirements for $3 \mathrm{~d}$ models of virtual scenes. Driving simulator scenarios are most commonly created using the TIN (triangulated irregular network) model [3]. With such a representation, the models are being created within an irregular network of triangles. These models should be as maximally close to reality as well as being simple (composed of the minimum possible number of triangles). Another important requirement are the models, which are not visible to a driver (proband), needn't be created. The last requirement would be the complexity of a model inversely proportional to the object's distance from the road axis.

Application of these approaches makes it possible to use the less powerful hardware for creating virtual sceneries for driving simulator. Optimized 3D scene models allow higher frame rates for the projected scenes, which provides a better illusion of a real world. 

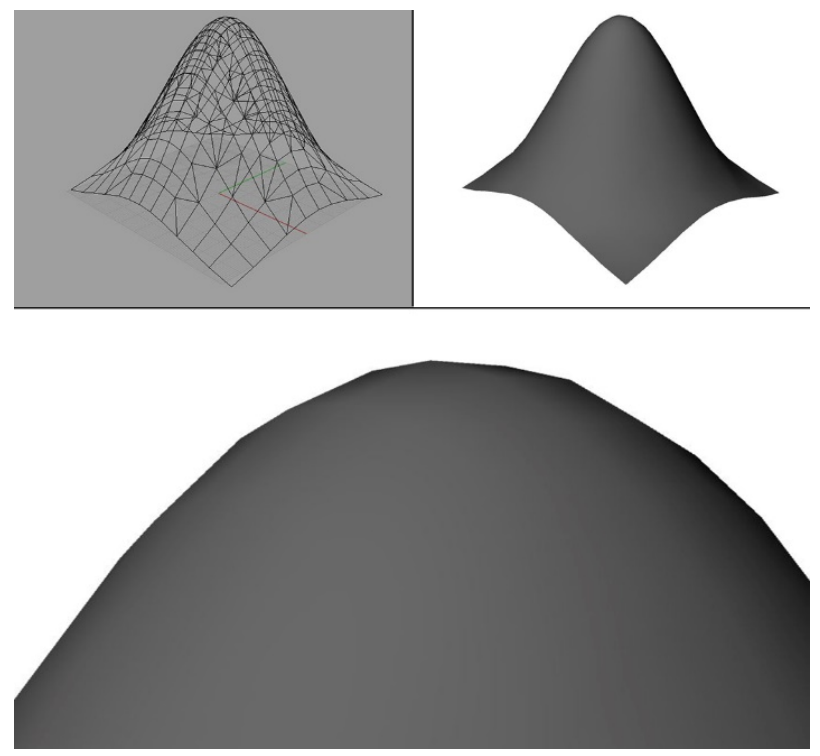

Figure 1. TIN models.

\section{Plug-in Road Creator for RHINO}

Plug-in Road Creator for Rhino was created for 3D modeling and visualization program Rhinoceros. The program is focused on creating models in NURBS (Non-uniform rational basis spline) representation, where objects are mathematically described with the help of control points and their importance 4. Thus, the objects are more precise and don't contain sharp edges. This kind of representation is also valuable for the possibility of further transformation of $3 \mathrm{D}$ model into TIN model, for which it is possible to optimize the count of triangles of the model itself and thus optimize models for a driving simulator scene.

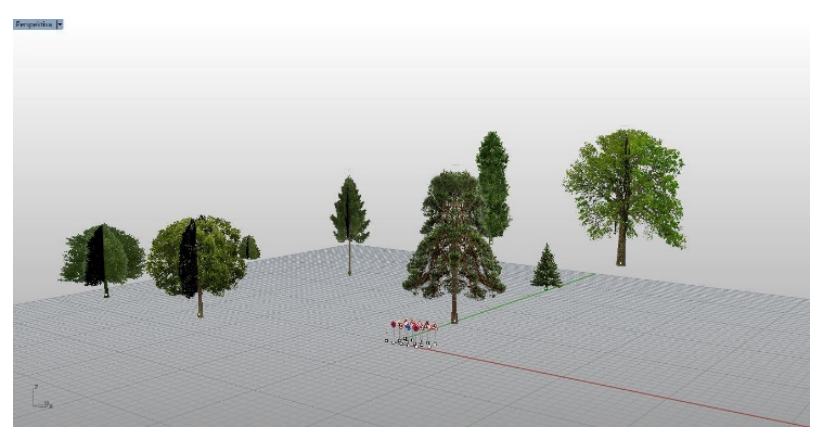

FiguRE 2. NURBS models.

In the created plug-in it is possible to generate $3 \mathrm{D}$ models of road infrastructure (according to Czech standard ČN 73 6101) into the Rhinoceros software[2]. The Standard is about the creation of designing roads and highways in the Czech Republic. Other important elements in the infrastructure are generated per the corresponding standards and technical specifications.

The plug-in was designed in a way that allows fast generating of the driver simulator scenes. That's why databases with modelled objects was created for plugin. Overall two databases have been formed. The first one is the database named "Trees" that contains models of trees, bushes and grass and it is necessary for the completion of vegetation in the scene. The second database named "Buildings" contains building and specific elements present around the roads.

Plug-in contains 54 new functions, due to which the scene creation is not as difficult as it used to be before. For user convenience, all the functions have been placed on a specially created control panel. For possible viewing of the scene model, the plug-in structures have newly created objects as layers.

\subsection{Plug-in FunCtions}

The plug-in was created for the creation of driving scenarios. The creation of road infrastructure deploys five groups of functions of the plug-in. Those include:

- 2D Road,

- 3D Road,

- Extras,

- Nature,

- City.

The functions can be accessed from the interface toolbar (see Figure 3 for reference).

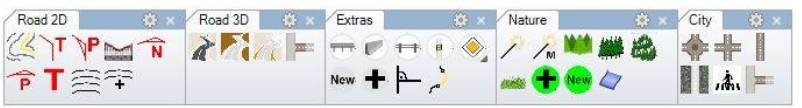

Figure 3. Plug-in functions (interface toolbar).

The process itself consists of four sequential stages. Schematic and logical representation is shown in Figure 11.

Stage 1 (Model pre-processing) serves for the creation of a terrain model which is the basis of a road network. For transferring the $3 \mathrm{D}$ terrain model into the contour lines the function "contour lines" from the first group is applied (see Figure 4).

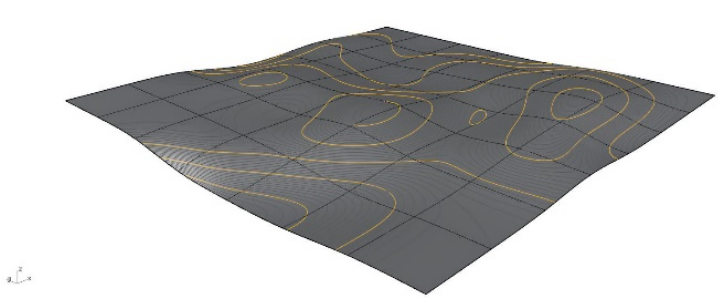

Figure 4. Terrain transfer to contour lines.

At stage 2 basic curves for the future road communication are created using the functions from $2 \mathrm{D}$ group. With the help of horizontal (successive use of functions "tangential polygon", "arch with transition curve", and "vertical alignment" + "tangential polygon" from Road 2D group) and vertical (functions "vertical alignment" and "parabolic arch") alignment combination a road track is created (see Figure 5). 
By adding the cross-section type from the defined database of the cross-sections one defines the character of the road being created, i.e. number of lanes, their width etc. The database contains the crosssections corresponding to classes of the road defined in Czech Standard ČSN 736101.

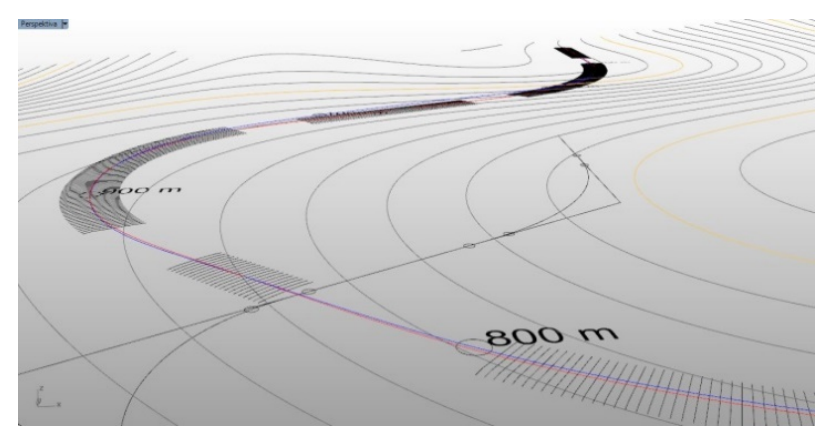

FigURE 5. Creation of road track.

The plug-in provides automatic modification of the cross-sections according the curvatures and with respect to the location coordinates (e.g., at intersections) on the created road track (see Figure 6).

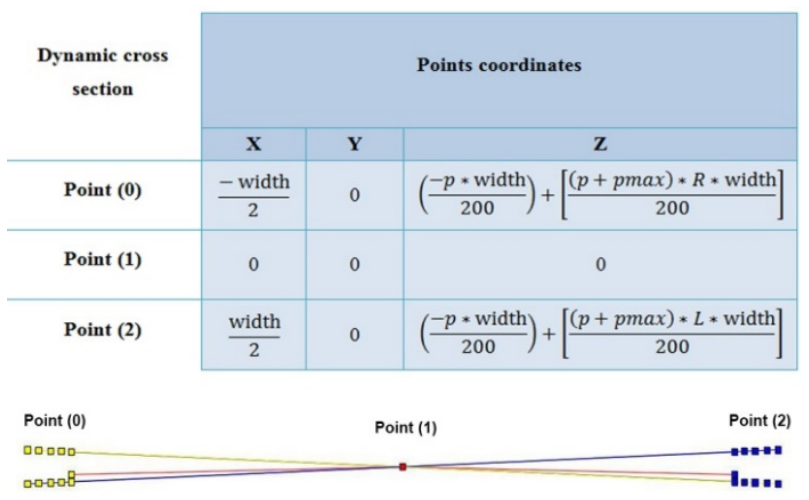

Figure 6. Basic road curves.

Now, when the basic curves are created, the 3D model of the road track can be created by using the function "3D road" from the "Road 3D" menu section the 3rd stage of the process. For the integration of the model into the terrain the function "Slopes" is applied. See the result in Figure 7 .

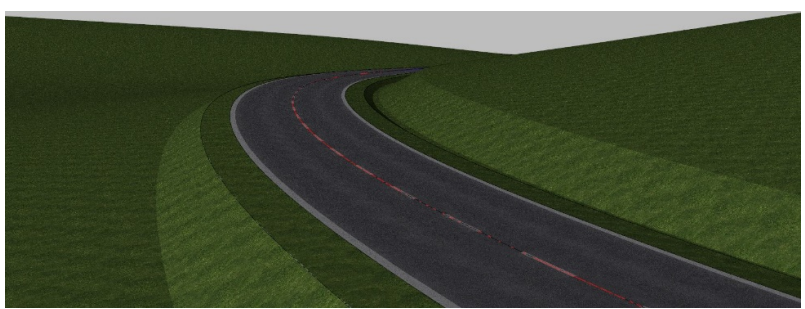

FiguRe 7. Road with slopes, 3D model.

The 4th stage is the final one, it results in a complete road track model that includes such attributes as barriers, traffic signs, pillars etc. See example on Figure 8

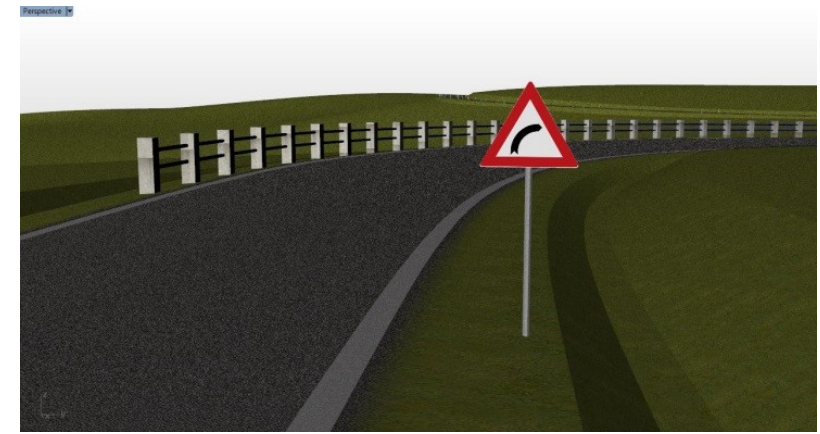

Figure 8. Complete road track model.

With the help of the plug-in described, it is also possible to create other scenario attributes, such as nature, buildings etc. See the final model example in Figure 9

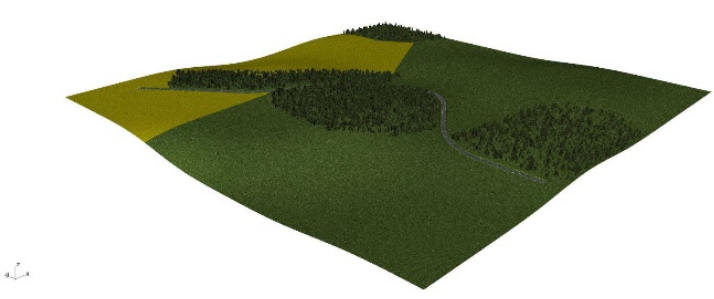

Figure 9. Final 3D model.

For the creation of the basic city infrastructure, a group of functions "City" shall be applied. These functions allow creation of different intersection types (see example in Figure 10, sidewalks, pedestrian crossings etc.

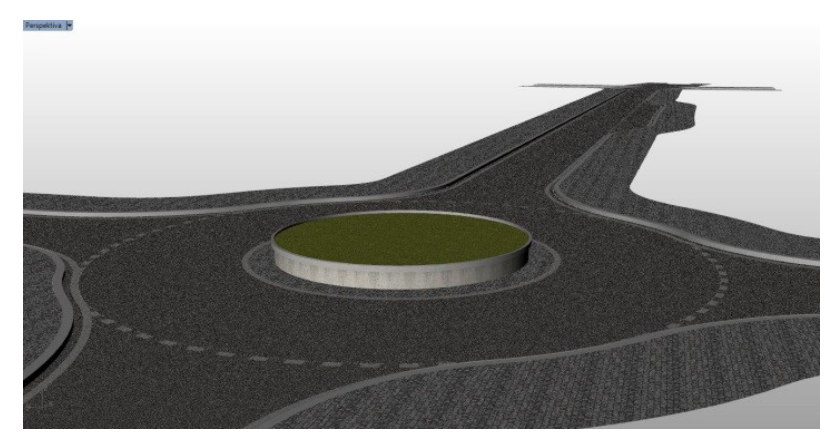

FigURE 10. City infrastructure - roundabout model.

\section{Conclusions}

The developed plug-in is nowadays unique regarding its possibility to create NURBS models of road infrastructure according to standard ČSN 73 6101. Unlike the TIN models, the NURBS models are more precise, while there is a possibility of transformation of NURBS models into TIN models with setting the quality of created TIN models in Rhinoceros software. The advantage is quality of TIN models can be optimized for driving simulators. During the transferring 


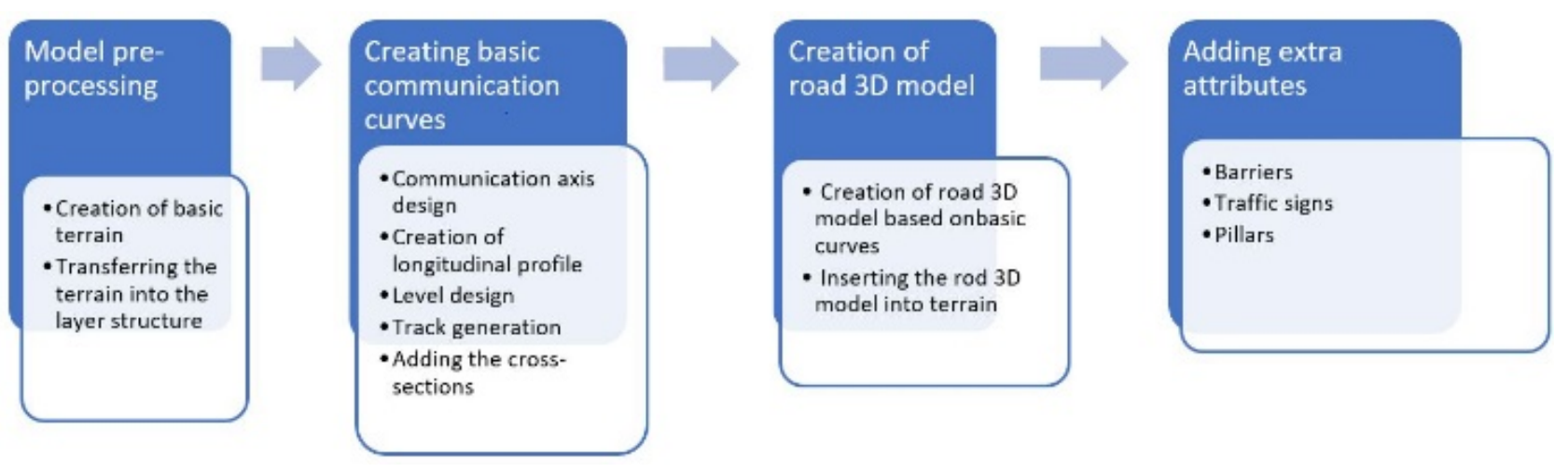

FIGURE 11. Road infrastructure creation process.

it has been accomplished that the models in simulator are not containing visible sharp transitions and are being formed with minimal possible number of triangles. The created 3D road infrastructure models can be also used for visualization, the plug-in can also be applied for schematic drawings of track situation and longitudinal profile, which can be used for the project documentation. Besides, the major advantage of this plug-in is that it significantly reduces the time spent at modeling. Creation of 3D scenery models with road infrastructure in this plug-in is the matter of several minutes.

After processing of the created infrastructure in the $3 \mathrm{D}$ modeling engine the scenario for simulation is ready (see Figure 12 .

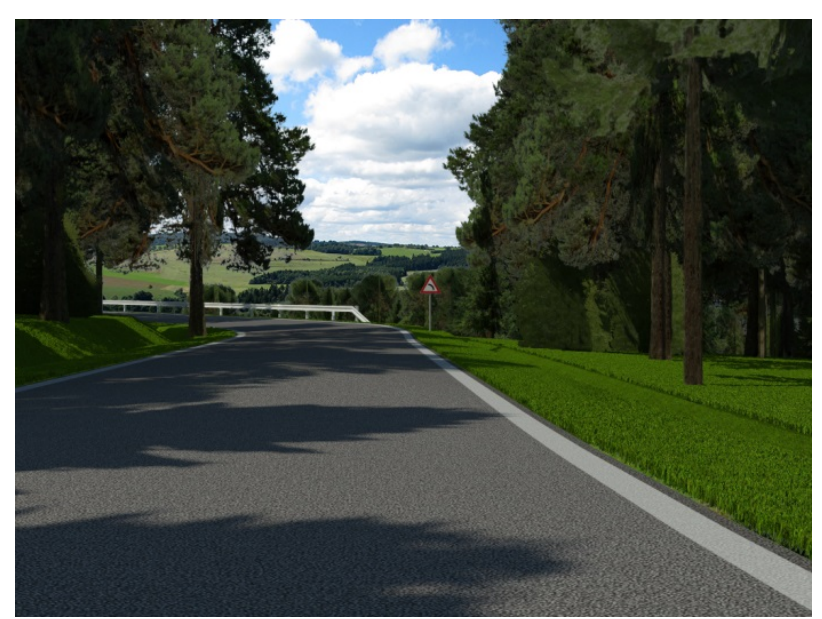

Figure 12. Final simulation scenario.

The plug-in is presently being used at Transportation Faculty at Czech Technical university in Prague as a main tool for generation of scenes for driving simulators. The functions of these plug-ins were also used for the creation of animations and visualizations in the final theses of students studying at the faculty of the author.

\section{REFERENCES}

[1] Road Design by Autocad Civil 3D and 3D Max Design. Youtube [online]. 2014 [cit. 2016-04-29]. Dostupné z: https://www.youtube.com/watch?v=eEo0wabU7ow.
[2] ČSN 736101 Projektování silnic a dálnic. Praha: Český normalizační institut, 2004.

[3] Počítačová grafika: Základy počítačové grafiky. ICT kompetence [online]. Olomouc: Katedry technické a informační výchovy PdF UP. [cit. 2016-04-29]. Dostupné z: http://www.kteiv.upol.cz/frvs/ictkubricky/?page= pocitacova-grafika/pocitacova-grafika.

[4] Rhino Developer Docs [online]. Robert McNeel \& Associate, @1997-2016 [cit. 2016-04-30]. Dostupné z: http://developer.rhino3d.com/. 